\title{
Pneumococcal infection in the newborn
}

\author{
R A Primhak, M S Tanner, R C Spencer
}

\begin{abstract}
Two fatal cases of invasive pneumococcal disease in the newborn are reported, both acquired from the maternal vagina. The rarity of vaginal carriage of pneumococcus suggests that this organism has a higher invasion to colonisation ratio than group B streptococcus and maternal carriage or neonatal colonisation should be more aggressively treated.

(Arch Dis Child 1993; 69: 317-318)
\end{abstract}

Streptococcus pneumoniae (pneumococcus) has been estimated to be responsible for $2 \%$ of all neonatal sepsis. ${ }^{1}$ Invasive neonatal pneumococcal disease is often compared to group B streptococcus in its clinical features and severity. ${ }^{23}$ We describe two recent cases of pneumococcal sepsis in the newborn and suggest that greater significance should be attached to the discovery of neonatal colonisation with pneumococcus.

\section{Case reports \\ CASE 1}

A 27 year old mother gave birth vaginally to a $2560 \mathrm{~g}$ girl 25 hours after membrane rupture. No resuscitation was required. At 13 hours the baby was noted to be pale, cyanosed and tachypnoeic, and required vigorous resuscitation and transfer to the subregional neonatal intensive care unit. The white cell count was $1 \cdot 75 \times 10^{9} / 1(22 \%$ neutrophils $)$, and a chest $x$ ray film showed widespread coarse consolidation. Despite treatment from the onset of symptoms with penicillin and gentamicin she developed intractable pulmonary hypertension requiring inotropic support, tolazoline and prostacycline, and died at 48 hours of age. Culture of surface swabs sent after delivery, blood at 13 hours, and maternal high vaginal swab all grew pneumococcus.

\section{CASE 2}

A 31 year old multiparous woman delivered a $3290 \mathrm{~g}$ boy 24 hours after membrane rupture.

University of Sheffield, Department of Paediatrics R A Primhak M S Tanner

\section{Department of Microbiology} R C Spencer

Correspondence to: Dr R A Primhak, Children's Hospital, Sheffield S10 2TH. Accepted 14 April 1993
No resuscitation was required. A high vaginal swab had been taken from the mother before delivery, and surface swabs were sent from the baby. No treatment was given, and after 24 hours uneventful observation the baby and mother were discharged from hospital. The next day pneumococcus was isolated from all swabs. The family doctor was informed, but no treatment was started in view of the baby's wellbeing.

Three days later the baby was admitted to hospital with a two day history of poor feeding. On admission he was irritable and febrile, and blood and cerebrospinal fluid both grew pneumococcus. Treatment with penicillin and cefotaxime was initiated rapidly after admission, but the baby developed renal failure and intractable seizures and died at the age of 3 weeks.

REVIEW OF MICROBIOLOGICAL RESULTS

All high vaginal, cervical, urethral, and genital swabs processed in the microbiology laboratory serving south Sheffield between 1987 and 1991 were reviewed. During this five year period over 15000 swabs from the above sites were processed and only five were positive for pneumococcus.

\section{Discussion}

In 1990 Geelen et al reviewed the literature for the clinical features of neonatal pneumococcal sepsis and summarised 43 cases. ${ }^{4}$ Half the cases occurred in preterm babies, and $43 \%$ had rupture of membranes more than 24 hours before delivery. Presentation was within 48 hours of birth in $90 \%$ of the cases, and the mortality was $50-60 \%$. Geelen et al and other authors have commented on the resemblance of this clinical picture to group B streptococcal sepsis. ${ }^{1-3}$ Between $8-23 \%$ of pregnant women carry group B streptococcus in the genital tract. Although colonisation of the baby is usual, the incidence of invasive disease is much lower, with a colonisation to infection ratio of about 100:1.5 In light of these data it is not unreasonable to withhold treatment where a baby is found to be colonised with group B streptococcus but is asymptomatic.

Neonatal pneumococcal sepsis is usually of early onset and prior bacteriology results may not be available. On occasion, however, a maternal swab taken before delivery may reveal pneumococcal colonisation in an asymptomatic baby, as in case 2 . Should such a baby receive antibiotic treatment? The rarity of vaginal carriage of this organism, ${ }^{6}$ coupled with the fact that pneumococcal sepsis is responsible for $2-5 \%$ of all neonatal sepsis ${ }^{14}$ suggests a higher invasion to colonisation ratio than for group B streptococcus. We recognise that it is not possible to set 'gold standard' policies based on the limited data available. However, in view of the serious nature of the invasive disease, we would recommend presumptive treatment of babies colonised with pneumococcus, or born to colonised mothers, even if asymptomatic. 
1 Westh H, Skibsted L, Korner B. Streptococcus pneumoniae infections of the female genital tract and in the newborn child. Rev Infect Dis 1990; 12: 416-22.

2 Bortolussi R, Thompson TR, Ferrieri P. Early-onset pneumococcal sepsis in the newborn. Pediatrics 1977; 60: 352-5.

3 Jacobs J, Garmyn K, Verhaegen J, Devlieger H, Eggermon E. Neonatal sepsis due to Streptococcus pneumoniae. Scand F Infect Dis 1990; 22: 493-7.
4 Geelen SPM, Gerards LJ, Fleer A. Pneumococcal septicaemia in the newborn. A report on seven cases and a review of the literature. 7 Perinat Med 1990; 18: $125-8$

5 Baker CJ, Barrett FF. Transmission of group B streptococcus among parturient women and their neonates. $f$ Pediatr 1973; 83: 919-25.

6 Beargie R, Lynd P, Tucker E, Duhring J. Perinatal infection and vaginal flora. Am $\mathcal{f}$ Obstet Gynecol 1975; 122: 31-3. 